\title{
A Clinico-Epidemilogical Study of Cases of Locally Advanced Non-Small Cell Lung Cancer (NSCLC) that Received Radiotherapy at NCI Cairo in the Period from 2001-2010
}

\section{Mohamed Lotayef ${ }^{1 *}$, Azza Taher ${ }^{1}$, Hanna Attia ${ }^{2}$, Azza Nasr ${ }^{1}$, Hishamel Hossieny ${ }^{1}$, Mohammed Mahmoud ${ }^{1}$ and Noha Essam ${ }^{1}$}

${ }^{1}$ Radiation Oncology Department, National Cancer Institute, Cairo University, Egypt

${ }^{2}$ Clinical Oncology Department, Faculty of medicine, Cairo University, Egypt

\begin{abstract}
Purpose: This work was to study the clinic-epidemiological characteristics of patients with locally advanced NCSLC and to analyze their prognostic factors and also the results of different treatment modalities for local control and their effect on overall survival (OAS)
\end{abstract}

Materials and methods: This is a retrospective study included 121 patients with primary locally advanced NSCLC diagnosed between 2001 and 2010 at the radiotherapy department, National Cancer Institute, Cairo University, Egypt.

Results: The study showed significant correlation between the tumor size $\leq 7 \mathrm{~cm}$, old age $>60$, moderately differentiated tumors $\mathrm{G} 2$ and treatment outcomes; better locoregional control and better survival rates. On the opposite side poorly differentiated tumors $\mathrm{G} 3$, tumor size $>7 \mathrm{~cm}$ had the worst locoregional control and survival rates. The study also showed significant statistical correlation between treatment modality, locoregional control and survival rates. Patients who were treated by either concomitant chemo-radiotherapy or sequential chemoradiotherapy had better local control compared to other patients who were treated by radical radiotherapy, and they also had the best survival rates among all the other treatment groups. The average 6 months OAS rates for all studied patients were $60.3 \%$ while 12 months survival rates were $38.8 \%$. The median OAS was 7 months. The data was summarized by descriptive statistics [i.e., mean, standard deviation (SD), frequencies]. Mean values and standard deviation were compared using simple T-test ( 2 variables). Percentages were compared using Chi-square test or Fisher's exact test. Kaplan-Meier test was used for predictive survival rates.

Conclusions: From the present study, we concluded that concomitant chemradiotherapy is the treatment of choice for locally advanced non small cell lung cancer; also we concluded that better performance status and higher hemoglobin levels have better treatment outcome in these cases.

\section{Keywords: NSCLC; NCI Cairo; Retrospective trial}

\section{Introduction}

In the National Cancer Institute (NCI) in Egypt, malignant tumors of the lower respiratory system including the lungs and bronchi constituted $24.16 \%$ of respiratory organ malignancies and $1.54 \%$ of total malignancy with high Male predominance [1].

Radiation therapy plays an important role in the palliation of symptomatic intrathoracic disease. Such symptoms include dyspnea, cough, hemoptysis, and/or chest pain. Common schemes include $10 \mathrm{~Gy}$ in a single fraction, $17 \mathrm{~Gy}$ in two fractions, and $30 \mathrm{~Gy}$ in ten fractions. More conventional 5 or 6 week courses have also been used. In general, for symptomatic patients with locally advanced tumors not suitable for curative therapy, abbreviated RT courses have provided similar symptom control and survival compared to more protracted regimens. Regarding relation between $r$ th and chemo, The superiority of concurrent chemotherapy with radiation therapy compared with sequential chemotherapy followed by irradiation was conclusively demonstrated in large multicenter trials $[2,3]$.

\section{Patients and Methods}

This is a retrospective study of patients with primary locally advanced NSCLC diagnosed between 2001 and 2010 at the radiotherapy department, National Cancer Institute, Cairo University, Egypt; it included 121 patients who were properly staged. In all patients with complete file data we studied the clinic-epidemiological characteristics of the patients, analyze the prognostic factors and also we analyzed the results of different treatment modalities for local control and their effect on overall survival (OAS).

\section{Statistical analysis}

The data was summarized by descriptive statistics [i.e., mean, standard deviation (SD), frequencies]. Mean values and standard deviation were compared using simple $t$ test (2 variables). Percentages were compared using Chi-square test or Fisher's exact test. Logistic regression was used whenever the dependant factor was binary in nature (e.g. yes or no) during multivariate analysis. Kaplan-Meier test was used for predictive survival rates. The software used on the analysis was (Version 15; SPSS Institute, Cary, NC, USA, Graph pad instat 2008) and a $P$ value less than 0.05 was considered to be statistically significant.

*Corresponding author: Mohamed Lotayef, Lecturer, National Cancer InstituteCairo University, Radiation Oncology, Foam Elkhalig squre- Cairo, Cairo, EGYPT Tel: +201001536681; E-mail: m mahmoud1973@yahoo.com

Received March 07, 2014; Accepted April 14, 2014; Published April 16, 2014

Citation: Lotayef $M$, Taher A, Attia H, Nasr A, Hossieny $H$, Mahmoud M, et al (2014) A Clinico-Epidemilogical Study of Cases of Locally Advanced Non-Small Cell Lung Cancer (NSCLC) that Received Radiotherapy at NCl Cairo in the Period from 2001-2010. J Cancer Sci Ther 6: 151-155. doi:10.4172/1948-5956.1000264

Copyright: $\odot 2014$ Lotayef M, et al. This is an open-access article distributed under the terms of the Creative Commons Attribution License, which permits unrestricted use, distribution, and reproduction in any medium, provided the original author and source are credited. 
Citation: Lotayef M, Taher A, Attia H, Nasr A, Hossieny H, Mahmoud M, et al. (2014) A Clinico-Epidemilogical Study of Cases of Locally Advanced Non-Small Cell Lung Cancer (NSCLC) that Received Radiotherapy at NCl Cairo in the Period from 2001-2010. J Cancer Sci Ther 6: 151155. doi:10.4172/1948-5956.1000264

For all patients, overall survival was calculated starting from date of presentation to the date of death and was also correlated with different prognostic factors.

\section{Results}

The study included 121 patients who were properly staged. Patients who didn't have proper initial staging or pre-treatment evaluation were excluded.

On comparing radiotherapy completion with haemoglobin levels we found that most of the patients who completed radiotherapy (91\%) had hemoglobin level $\geq 11 \mathrm{mg} / \mathrm{dl}$ with a P-value which was highly significant $<0.001$, while $91 \%$ of patients who were treated with radical treatment completed their full course of radiotherapy, while $74 \%$ of patients who were treated with palliative treatment completed their prescribed radiotherapy course with a P-value which was significant $=0.012$. Response of the patients to treatment was assessed radiologically and clinically. Fifty one patients had partial response (42\%), forty seven patients were stable (38.8\%) and eight patients had progressive disease $(6.6 \%)$ none of the patients achieved complete response.

Regarding distant metastases only 17 patients had distant metastases which were diagnosed during or after finishing their treatment course (14\%). Nine patients had brain metastases while eight patients had bone metastases.

The 6 month and the 12 months overall survival were calculated for all patients and for the different prognostic factors separately and then for each group according to the type of treatment they received. In all groups the 6 months overall survival was $60.3 \%$ and the 12 month overall survival was $38.8 \%$.

Younger Patients with locally advanced non small cell lung cancer with age $\leq 60$ showed higher overall survival compared to older patients with age $>60$, $(\mathbf{P}$-Value=0.038) $($ Figure 1$)$.

Patients with performance status 0 and 1 showed significantly higher overall survival with average survival of 17 months compared with those with performance status 2 and 3 who had an average survival of 7 months, (P-value<0.001) (Figure 2).

Survival rate was significantly higher among patients with grade 2 than grade 3 tumors; 12 months survival rate was $43.5 \%$ for grade 2 tumors, 32.7\% for grade 3 tumors, (P-value $<\mathbf{0 . 0 0 1}$ ) (Figure 3 ).

Survival rate among patients with hemoglobin equal or more than $11 \mathrm{mg} / \mathrm{dl}$ was higher than patients with hemoglobin less than $11 \mathrm{mg} / \mathrm{dl}$, (P-Value $<\mathbf{0 . 0 0 1}$ ) (Figure 4).

Survival rate was higher among patients with mass size less than or equal $7 \mathrm{~cm}$ compared with patients with mass size more than $7 \mathrm{~cm}$, (P-Value $<\mathbf{0 . 0 0 1}$ ) (Figure 5).

As expected, those who were treated with radical treatment had a better survival rate than those who were treated with palliative radiotherapy, $(\mathbf{P}$-Value $<\mathbf{0 . 0 0 1})$ (Figure 6).

In the radical group, survival rate was higher among patients treated with concomitant chemo-radiotherapy the one year survival was $(92.9 \%)$ while it was $(55.9 \%)$ for those patients who received sequential chemo-radiotherapy and $(20 \%)$ for patients received radical radiotherapy only, $(\mathbf{P}$-value $=\mathbf{0 . 0 0 1})$ (Figure 7$)$.

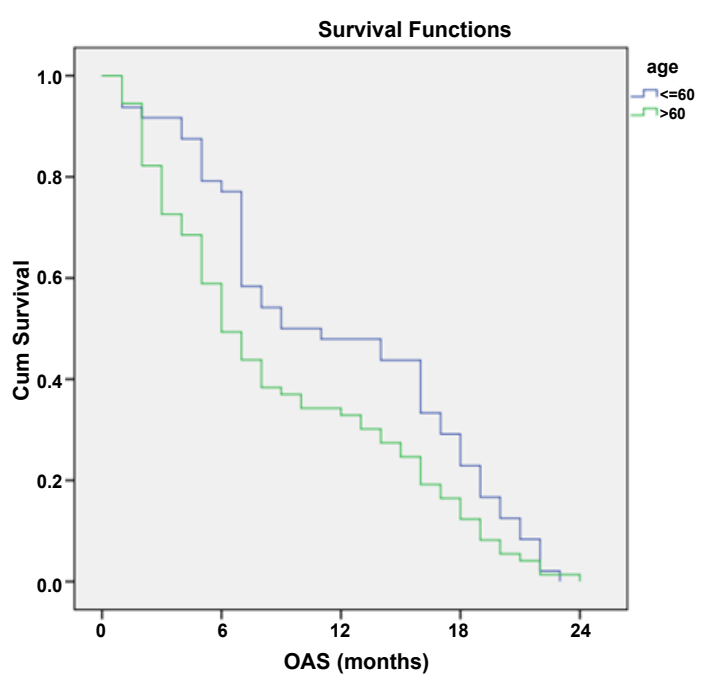

Figure 1: Overall survival compared to age.

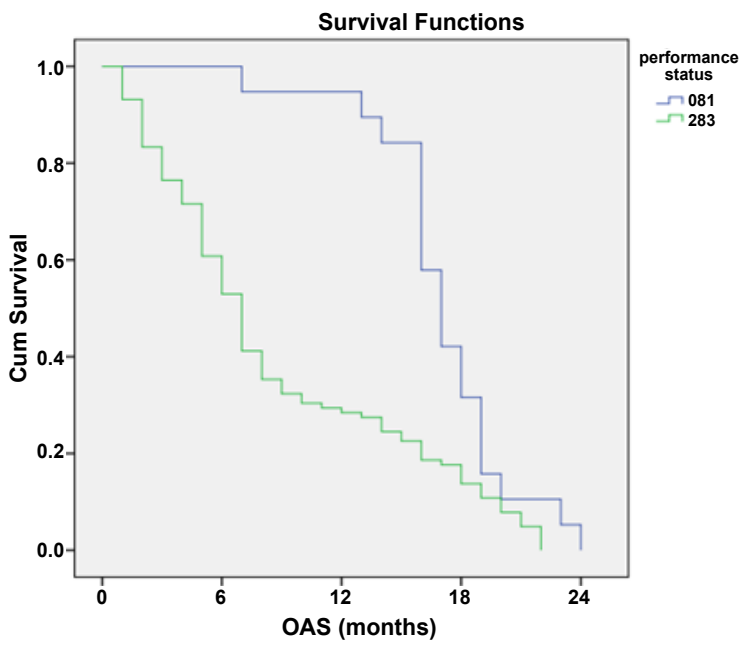

Figure 2: Overall survival compared to performance status.

Finally patients who had partial response had higher survival rate than those patients with stable response, $(\mathbf{P}$-value<0.001) (Figure 8).

\section{Discussion}

In the current study most of patients had positive history for smoking (87.6\%) while only (12.4\%) were non smokers also Ries LAG et al. found that $90 \%$ of lung cancer is associated with cigarette smoking [4].

In the current study the most common histopathological type was squamous cell carcinoma $(51.2 \%)$, while $(31.4 \%)$ of the patients were diagnosed as adenocarcinoma while in the WHO classification for primary lung cancer they recognizes three major histologic cell types with approximate frequencies as follows : adenocarcinoma (38\%), Squamous cell carcinoma is (20\%) and large cell carcinoma is (5\%) measured by surveillance, epidemiology and end results (SEER). This 
Citation: Lotayef M, Taher A, Attia H, Nasr A, Hossieny H, Mahmoud M, et al. (2014) A Clinico-Epidemilogical Study of Cases of Locally Advanced Non-Small Cell Lung Cancer (NSCLC) that Received Radiotherapy at NCl Cairo in the Period from 2001-2010. J Cancer Sci Ther 6: 151155. doi:10.4172/1948-5956.1000264

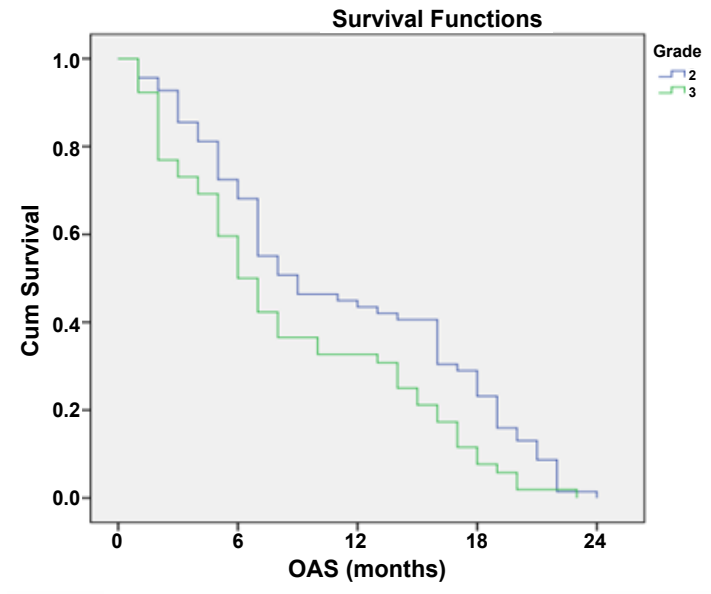

Figure 3: Overall survival compared to tumor grade.

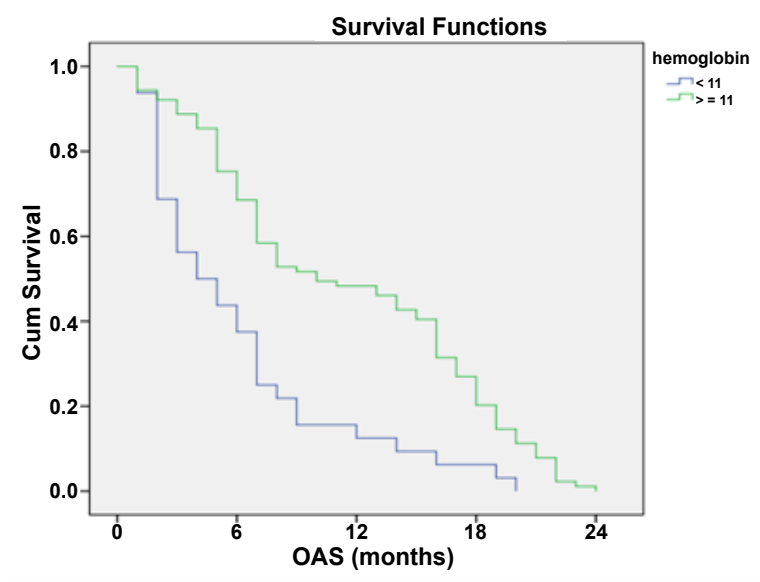

Figure 4: Overall survival compared to hemoglobin level.

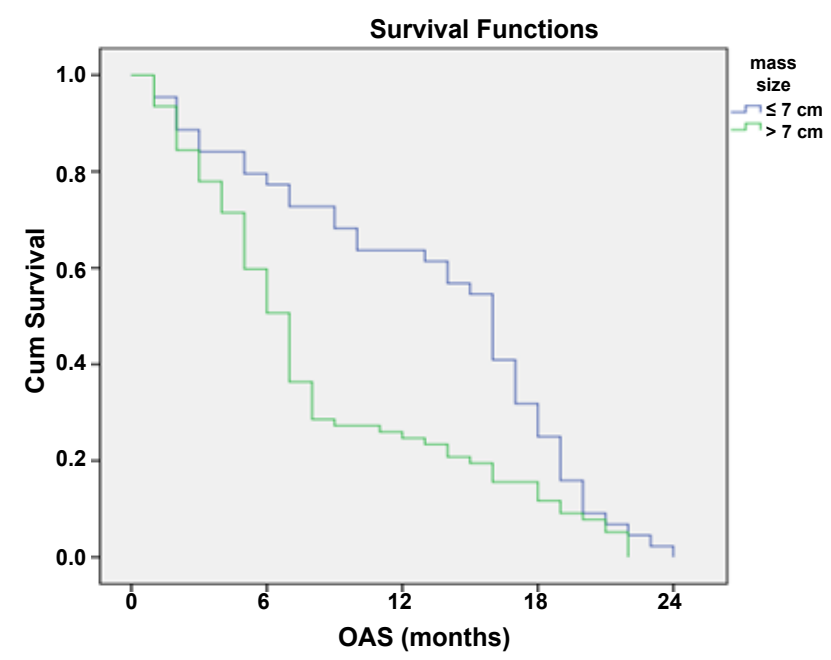

Figure 5: Overall survival compared to mass size.

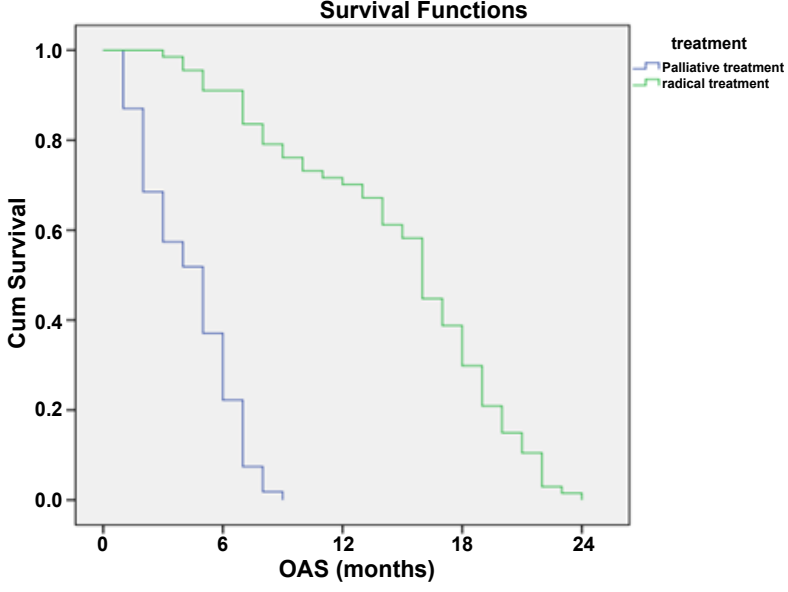

Figure 6: Overall survival compared to purpose of treatment.

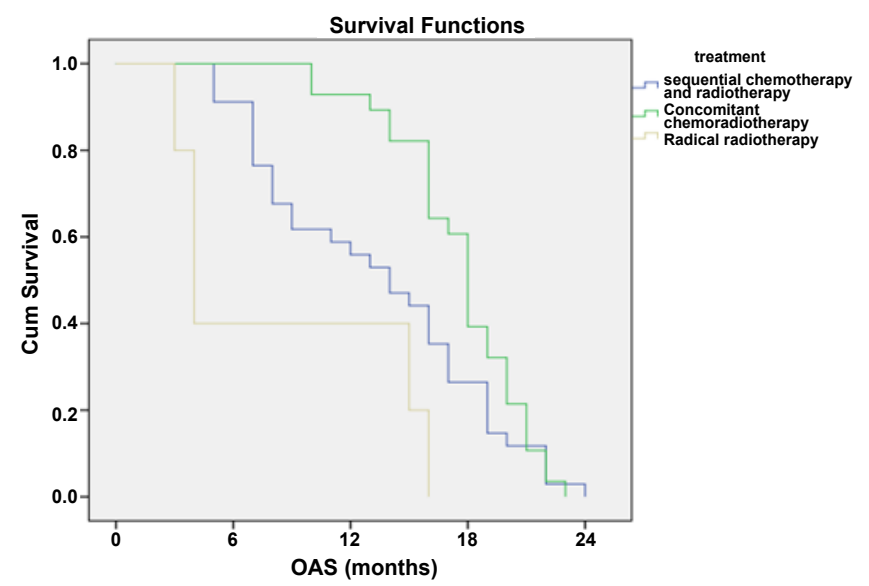

Figure 7: Overall survival compared to type of treatment.

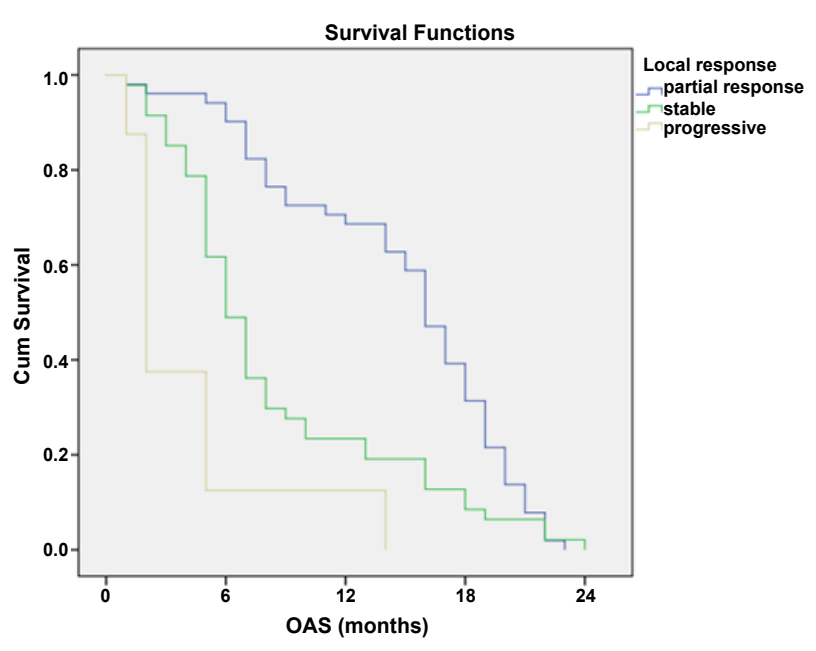

Figure 8: Overall survival compared to type of response. 
Citation: Lotayef M, Taher A, Attia H, Nasr A, Hossieny H, Mahmoud M, et al. (2014) A Clinico-Epidemilogical Study of Cases of Locally Advanced Non-Small Cell Lung Cancer (NSCLC) that Received Radiotherapy at NCl Cairo in the Period from 2001-2010. J Cancer Sci Ther 6: 151155. doi:10.4172/1948-5956.1000264

difference could be attributed to different habits as smoking (type and quality of tobacco), occupational exposure (Diesel fumes) or previous untreated chronic obstructive pulmonary disease which could play a role and need further investigations [5].

In this study we recorded the hemoglobin level for all patients, we found that $73.6 \%$ of patients had hemoglobin level $>11 \mathrm{mg} / \mathrm{dl}$, in spite of their poor general condition; this could be attributed to high $\mathrm{CO}_{2}$ tension which leads to compensatory hyperplasia by bone marrow which leads to elevated hemoglobin level.

Distant metastases were found in $14 \%$ of our patients during or after finishing their treatment course, in a study by Molina et al., he found that $40 \%$ of NSCLC will present or develop distant metastases during their treatment. The incidence of brain metastases in our study was $6.5 \%$, while in a study of NSCLC epidemiology by Molina et al., the incidence was $11 \%$. While In autopsy series done by Galluzzi et al., the incidence of brain metastases exceeded $25 \%$. Bone metastases was found in $7.5 \%$ of this study patients, which is comparable to what had been reported by other studies by Molina et al. and Kuchuka et al. [6-8].

In this current study, patients with poor performance status (ECOG 2\&3) showed worse local control than those with good performance status (ECOG 0 \& 1). Bezjak A et al., also identified poor performance status (i.e., ECOG PS 2) as a strongly negative prognostic variable with advanced NSCLC. Overall survival was also significantly affected by patients' performance that patients with good performance status (ECOG $0 \& 1$ ) had better OAS compared to those patients with poor performance status (ECOG 2\&3). These results were similar to the results published by Sculier JP. et al. $[9,10]$.

We found that poorly differentiated tumors (G3) had worse local response than those of moderately differentiated tumors (G2), similar confirmatory results were published by Takies A et al. [11].

Most of the patients had poor treatment outcomes as all the patients who were included in this study were diagnosed as locally advanced disease. Confirmatory results were published by Groome PA.et al., which mentioned that survival decreased progressively with more advanced disease (median of 59 months for patients with stage IA disease compared to four months for those with stage IV disease) [12].

In the current study we found that addition chemotherapy to radiotherapy had improved the OAS compared to radiotherapy alone (survival rate was higher among patients treated with concomitant chemo-radiotherapy the one year survival was (92.9\%) while it was $(55.9 \%)$ for those patients who received sequential chemoradiotherapy and (20\%) for patients received radical radiotherapy only. ( $\mathrm{p}$-value $=0.001$ ), this was similar to the results published by Branislav J. et al., [13].

Also we found that our results is similar to the result published by Fournel P. et al., which confirmed the superiority of concurrent chemotherapy with radiation therapy compared with sequential chemotherapy followed by irradiation. Also similar results were demonstrated by Zatloukal et al., [14,15].

Also Sause W.et al., [16] confirmed our data regarding a significant better OAS with sequential chemo-radiotherapy compared to radical radiotherapy. He studied two groups treated with radiotherapy alone or sequential chemo-radiotherapy and he found that median and overall survival were much higher in the sequential chemo-radiotherapy group $(23 \%$ with sequential chemo-radiotherapy group compared to
$11 \%$ with radiotherapy alone group).These findings were validated by the Radiation Therapy Oncology Group (RTOG) [13] which compared radical radiotherapy (two arms either daily to $60 \mathrm{~Gy}$ or daily to $69.6 \mathrm{~Gy}$ ) vs. sequential chemo-radiotherapy arm $[13,16]$.

The current study showed a significant correlation between local response and OAS, median survival of patients with partial response was 16 month which was higher than those with stable or progressive response (median survival rate was 6 and 2 month respectively). Similar results were published by Dong et al., who showed that patients with complete or partial response had improved 4-year overall survival rate compared to patients with no response (stable or progressive disease); $21.1 \%$ vs. $3.3 \%$ [17].

In this study we found a significant correlation between hemoglobin level and overall survival, patients with hemoglobin levels $>11 \mathrm{mg} / \mathrm{dl}$ had median survival of 10 months compared to 4 months for those patients with hemoglobin levels $<11 \mathrm{mg} / \mathrm{dl}$. Julio et al. had similar results regarding anemia which was associated with poor survival when hemoglobin concentration is less than $12 \mathrm{~g} / \mathrm{dl}$ [18].

\section{Conclusions and Recommendations}

This study matches the published data that support that concomitant chemo-radiotherapy is recommended as the treatment of choice for locally advanced non small cell lung cancer.

Locally advanced non small cell lung cancer is a very aggressive tumor. Most of the patients are presented with advanced late stage disease which is beyond radical treatment. Health education and screening programs are advisable for earlier tumor detection as the tumor stage is the most important prognostic factor for better survival rates.

Further studies on a larger series of patients and introducing new treatment protocols is necessary for final evaluation. Patients should be more involved in clinical trials to achieve the best treatment strategy for this aggressive disease also we need in the NCI to improve our radiation techniques to decrease as much as possible the radiation induced complications for better treatment outcome.

\section{References}

1. Nadia Mokhtar, Iman Gouda, Iman Adel (2004) Cancer Pathology Registry 2003-2004 and Time Trend Analysis 8:57

2. Curran WJ, Scott C, Langer C (2003) Long-term benefit is observed in a phase III comparison of sequential vs concurrent chemoradiation for patients with unresected stage III non-small cell lung cancer: RTOG 9410. Proc Am Soc Clin Oncol 22:621a.

3. Kong FM1, Zhao L, Hayman JA (2006) The role of radiation therapy in thoracic tumors. HematolOncol Clin North Am 20: 363-400.

4. Ries LAG, Harkins D, Krapcho M (2006) SEER Cancer Statistics Review, 1975-2003. National Cancer Institute.

5. Adamo MB, Johnson CH, Ruhl JL, Dickie, LA Dickie (2011) SEER Program Coding and Staging Manual. National Cancer Institute, NIH Publication number 11-5581, Bethesda, MD

6. Molina JR1, Yang P, Cassivi SD, Schild SE, Adjei AA (2008) Non-small cell lung cancer: epidemiology, risk factors, treatment, and survivorship. Mayo Clin Proc 83: 584-594.

7. GALLUZZI S, PAYNE PM (1955) Bronchial carcinoma: a statistical study of 741 necropsies with special reference to the distribution of blood-borne metastases. Br J Cancer 9: 511-527.

8. Kuchuka M, Addisonb C, Clemons M, Iryna K, Paul WP (2013) Incidence and consequences of bone metastases in lung cancer patients. J Bone Oncol2 22-29. 
Citation: Lotayef M, Taher A, Attia H, Nasr A, Hossieny H, Mahmoud M, et al. (2014) A Clinico-Epidemilogical Study of Cases of Locally Advanced Non-Small Cell Lung Cancer (NSCLC) that Received Radiotherapy at NCl Cairo in the Period from 2001-2010. J Cancer Sci Ther 6: 151155. doi:10.4172/1948-5956.1000264

9. Bezjak A1, Dixon P, Brundage M, Tu D, Palmer MJ, et al. (2002) Randomized phase III trial of single versus fractionated thoracic radiation in the palliation of patients with lung cancer (NCIC CTG SC.15). Int J RadiatOncolBiolPhys 54 719-728.

10. Sculier JP1, Chansky K, Crowley JJ, Van Meerbeeck J, Goldstraw P; International Staging Committee and Participating Institutions (2008) The impact of additional prognostic factors on survival and their relationship with the anatomical extent of disease expressed by the 6th Edition of the TNM Classification of Malignant Tumors and the proposals for the 7 th Edition. $\mathrm{J}$ ThoracOncol 3: 457-466.

11. Takise A1, Kodama T, Shimosato Y, Watanabe S, Suemasu K (1988) Histopathologic prognostic factors in adenocarcinomas of the peripheral lung less than $2 \mathrm{~cm}$ in diameter. Cancer 61:2083-2088.

12. Groome PA, Bolejack V, Crowley JJ, Kennedy C, Krasnik M, et al. (2007) The IASLC Lung Cancer Staging Project: validation of the proposals for revision of the $\mathrm{T}, \mathrm{N}$, and $\mathrm{M}$ descriptors and consequent stage groupings in the forthcoming (seventh) edition of the TNM classification of malignant tumours. J ThoracOncol 2:694

13. Jeremić B, Miličić B, Milisavljevic S (2012) Concurrent Hyperfractionated Radiation Therapy and Chemotherapy in Locally Advanced (Stage III) NonSmall-Cell Lung Cancer: Single Institution Experience with 600 Patients. Int J RadiatOncolBiolPhys82: 1157-1163.
14. Fournel $P$, Robinet $G$, Thomas $P$, Souquet PJ, Léna H, et al (2005) Randomized phase III trial of sequential chemoradiotherapy compared with concurrent chemoradiotherapy in locally advanced non-small-cell lung cancer: Groupe Lyon-Saint-Etienne d'OncologieThoracique-GroupeFrançais de PneumoCancérologie NPC 95-01 Study. J ClinOncol 23:5910-5917.

15. Zatloukal P1, Petruzelka L, Zemanova M, Havel L, Janku F, et al. (2004) Concurrent versus sequential chemoradiotherapy with cisplatin and vinorelbine in locally advanced non-small cell lung cancer: a randomized study. Lung Cancer 46: 87-98.

16. Sause W, Kolesar P, Taylor S IV, Johnson D, Livingston R, et al. (2000) Final results of phase III trial in regionally advanced unresectable non-small cell lung cancer: Radiation Therapy Oncology Group, Eastern Cooperative Oncology Group, and Southwest Oncology Group. Chest 117:358-364.

17. Kim DW1, Shyr Y, Chen H, Akerley W, Johnson DH, et al. (2005) Response to combined modality therapy correlates with survival in locally advanced nonsmall-cell lung cancer. Int J RadiatOncolBiolPhys 63: 1029-1036.

18. de Cos Escuín JS, Delgado IU, Rodríguez JC, López MJ, Vicente CD,et al. (2007) Stage IIIA and IIIB Non-Small Cell Lung Cancer: Results of Chemotherapy Combined With Radiation Therapy and Analysis of Prognostic Factors. Arch Bronconeumol 43: 358-365. 